\title{
A Method For Determining The Radially- Averaged Effective Impact Area For An Aircraft Crash Into A Structure
}

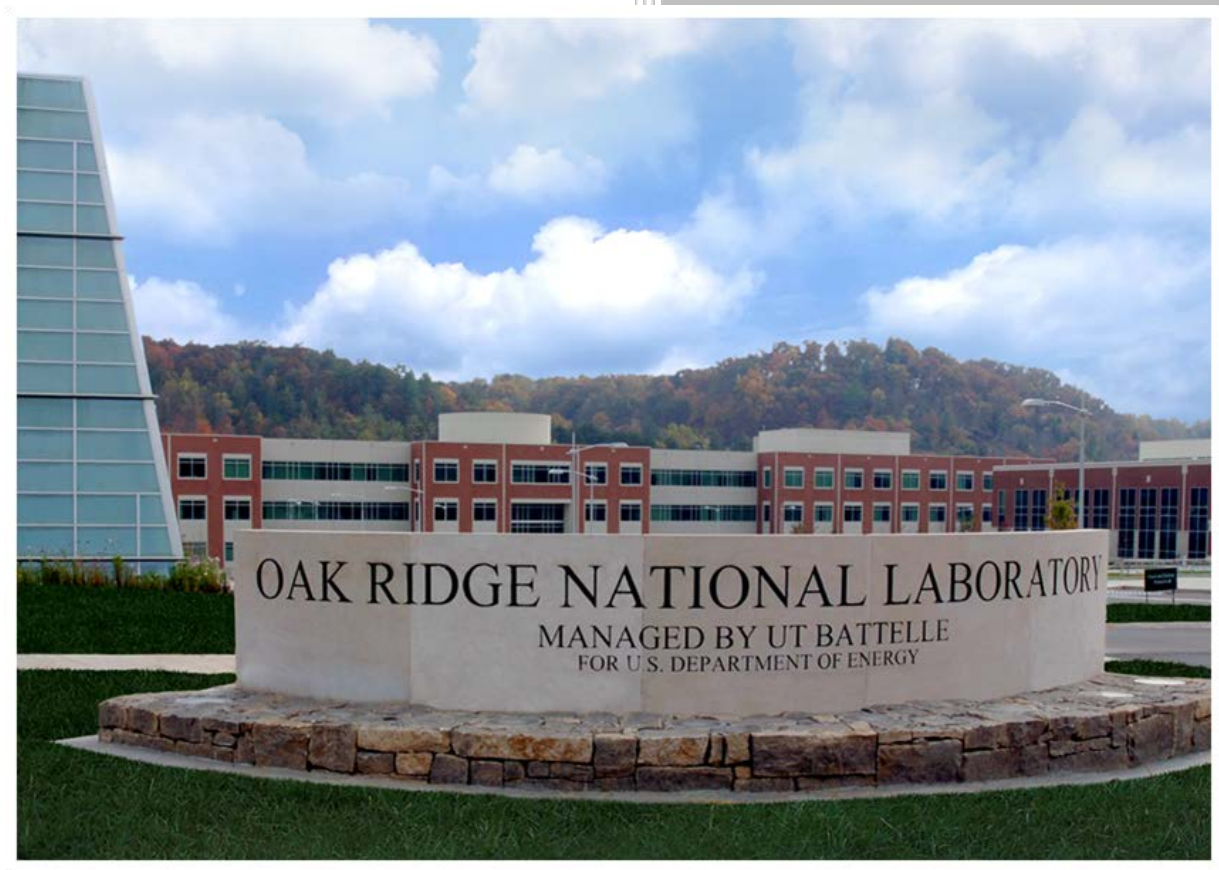

Approved for public release. Distribution is unlimited.

William C. Walker

February 2018 


\title{
DOCUMENT AVAILABILITY
}

Reports produced after January 1, 1996, are generally available free via US Department of Energy (DOE) SciTech Connect.

\section{Website http://www.osti.gov/scitech/}

Reports produced before January 1, 1996, may be purchased by members of the public from the following source:

\author{
National Technical Information Service \\ 5285 Port Royal Road \\ Springfield, VA 22161 \\ Telephone 703-605-6000 (1-800-553-6847) \\ TDD 703-487-4639 \\ Fax 703-605-6900 \\ E-mail info@ntis.gov \\ Website http://classic.ntis.gov/
}

Reports are available to DOE employees, DOE contractors, Energy Technology Data Exchange representatives, and International Nuclear Information System representatives from the following source:

Office of Scientific and Technical Information

PO Box 62

Oak Ridge, TN 37831

Telephone 865-576-8401

Fax 865-576-5728

E-mail reports@osti.gov

Website http://www.osti.gov/contact.html

This report was prepared as an account of work sponsored by an agency of the United States Government. Neither the United States Government nor any agency thereof, nor any of their employees, makes any warranty, express or implied, or assumes any legal liability or responsibility for the accuracy, completeness, or usefulness of any information, apparatus, product, or process disclosed, or represents that its use would not infringe privately owned rights. Reference herein to any specific commercial product, process, or service by trade name, trademark, manufacturer, or otherwise, does not necessarily constitute or imply its endorsement, recommendation, or favoring by the United States Government or any agency thereof. The views and opinions of authors expressed herein do not necessarily state or reflect those of the United States Government or any agency thereof. 
Nuclear and Radiological Protection Division

\section{A METHOD FOR DETERMINING THE RADIALLY- AVERAGED EFFECTIVE IMPACT AREA FOR AN AIRCRAFT CRASH INTO A STRUCTURE}

William C. Walker

Date Published: February 2018

Prepared by

OAK RIDGE NATIONAL LABORATORY

Oak Ridge, TN 37831-6283

managed by

UT-BATTELLE, LLC

for the

US DEPARTMENT OF ENERGY

under contract DE-AC05-00OR22725 
(This page intentionally blank) 


\section{CONTENTS}

CONTENTS

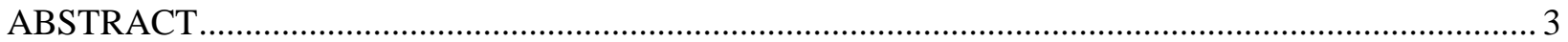

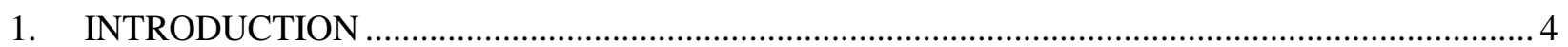

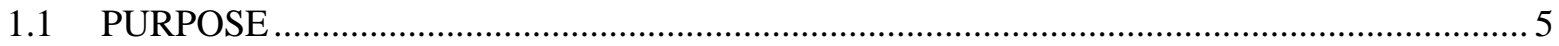

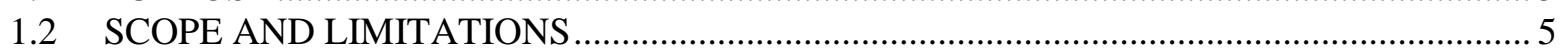

2. EFFECTIVE IMPACT AREA DERIVATION METHODOLOGY ................................................ 6

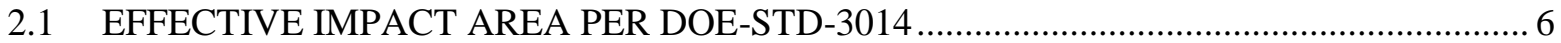

2.2 DERIVATION OF RADIALLY-AVERAGED EFFECTIVE IMPACT AREA ..................... 9

2.2.1 Application for Instances Where the Value for $\mathrm{N}_{\text {ops }}$ is not Radially-Dependent ........... 9

2.2.2 Application for Instances Where the Value for $\mathrm{N}_{\text {ops }}$ can be Radially-Dependent........ 11

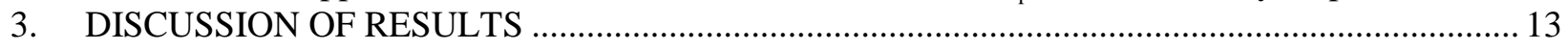

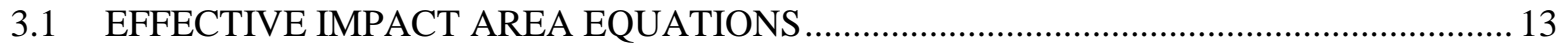

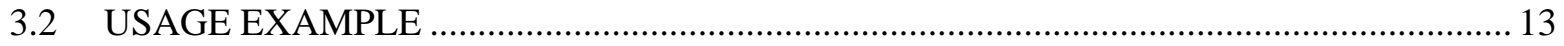

3.3 COMPARISON TO DOE-STD-3014 EFFECTIVE IMPACT AREA.................................. 15

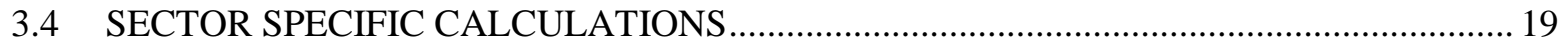

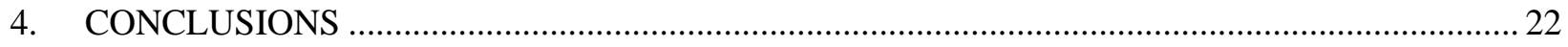

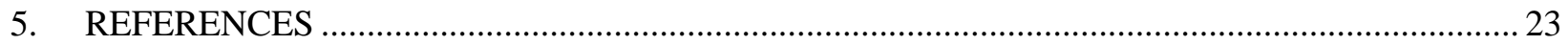

Appendix A. DERIVATION OF RADIALLY-AVERAGED EFFECTIVE IMPACT AREA

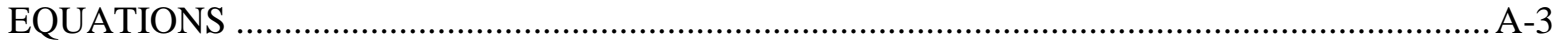


(This page intentionally blank) 


\begin{abstract}
This report presents a methodology for deriving the equations which can be used for calculating the radially-averaged effective impact area for a theoretical aircraft crash into a structure. Conventionally, a maximum effective impact area has been used in calculating the probability of an aircraft crash into a structure. Whereas the maximum effective impact area is specific to a single direction of flight, the radially-averaged effective impact area takes into consideration the real life random nature of the direction of flight with respect to a structure. Since the radially-averaged effective impact area is less than the maximum effective impact area, the resulting calculated probability of an aircraft crash into a structure is reduced.
\end{abstract}


(This page intentionally blank) 


\section{INTRODUCTION}

\subsection{PURPOSE}

The purpose of this report is to detail the inputs and assumptions associated with the calculation of the radially-averaged effective impact area for a hypothetical aircraft crash into a structure. The concept and use of the radially-averaged effective impact area is intended for use in the aircraft crash probability analysis described in DOE-STD-3014, “Accident Analysis for Aircraft Crash into Hazardous Facilities.” (1)

By convention, DOE-STD-3014 requires the use of a maximum effective impact area as defined by a aircraft impact at a specific direction of flight. However, under certain analytical situations as described in this report, the use of a radially-averaged effective impact area can be justified as a realistic representation of effective impact area. Using a radially-averaged impact area results in a lower calculated aircraft crash frequency into a structure since the radially-averaged effective impact area is less than the maximum effective impact area for structures with a rectangular footprint.

\subsection{SCOPE AND LIMITATIONS}

The analysis in this report is limited to derivation of a radially-averaged effective impact area for a structure with a footprint that is geometrically defined as a rectangle. As noted in DOE-STD-3014, structures with a footprint which are not rectangular shaped are subsequently analyzed as residing within a bounding rectangular footprint. The same limitations apply to the analysis in this report for nonrectangular shaped facilities. 


\section{EFFECTIVE IMPACT AREA DERIVATION METHODOLOGY}

\subsection{EFFECTIVE IMPACT AREA PER DOE-STD-3014}

Per DOE-STD-3014, “Accident Analysis for Aircraft Crash into Hazardous Facilities” ${ }^{(1)}$, the probability of an aircraft impact into a hazardous facility is determined via the a four-factor formula, which is summarized as follows:

$$
F=N_{\text {ops }} \cdot P \cdot f(x, y) \cdot A_{\text {eff }}
$$

Where;

F $\quad=$ Estimated annual aircraft crash impact frequency for the facility of interest; [crashes/y]

$\mathrm{N}_{\mathrm{ops}} \quad=$ Estimated annual number of site-specific aircraft operations; [operations/y]

$\mathrm{P} \quad=$ Aircraft crash rate; [crashes/operation]

$\mathrm{f}(\mathrm{x}, \mathrm{y})=$ Aircraft crash location conditional probability; $\left[\mathrm{mi}^{-2}\right]$

$\mathrm{A}_{\text {eff }} \quad=$ Site-specific effective area for the facility of interest; $\left[\mathrm{mi}^{2}\right]$

The effective area, $A_{\text {eff }}$, represents the ground surface area such that if an unobstructed aircraft were to crash within the area, it would impact the facility, either by direct fly-in or skid into the facility. The effective area depends on the length, width, and height of the facility, as well as on the aircraft's wingspan, flight path angle, heading angle relative to the heading of the facility, and the length of its skid. The effective area consists of two parts: the fly-in area and the skid area. The fly-in area is further divided into two parts, the footprint area and the shadow area. The footprint is the ground surface area occupied by a facility. The shadow area is the projected ground surface area corresponding to an aircraft impact into the facility. Finally, the skid area is the ground surface area corresponding to an aircraft ground impact with a subsequent skid into the facility. Figure 1 illustrates the skid area and the fly-in area for an aircraft with a direction of flight perpendicular to the southern-face of a facility. 


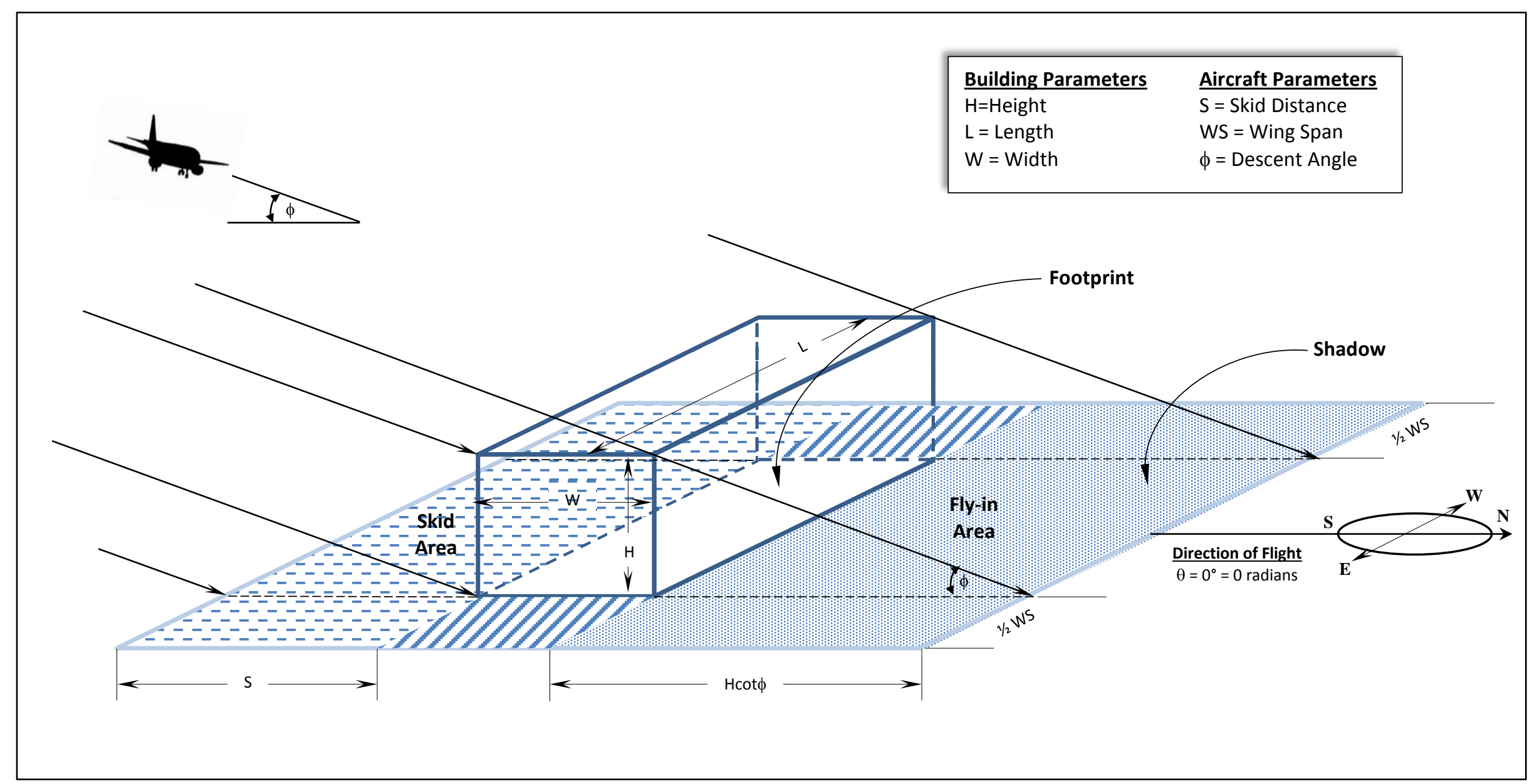

Figure 1 - Illustration of Aircraft Impact Area 
The equation for $\mathrm{A}_{\text {eff }}$ from DOE-STD-3014 is based on the facility being represented by a bounding rectangle, with the heading of the crashing aircraft with respect to the facility assumed to be perpendicular to the diagonal of the bounding rectangle, as shown in Figure 2.

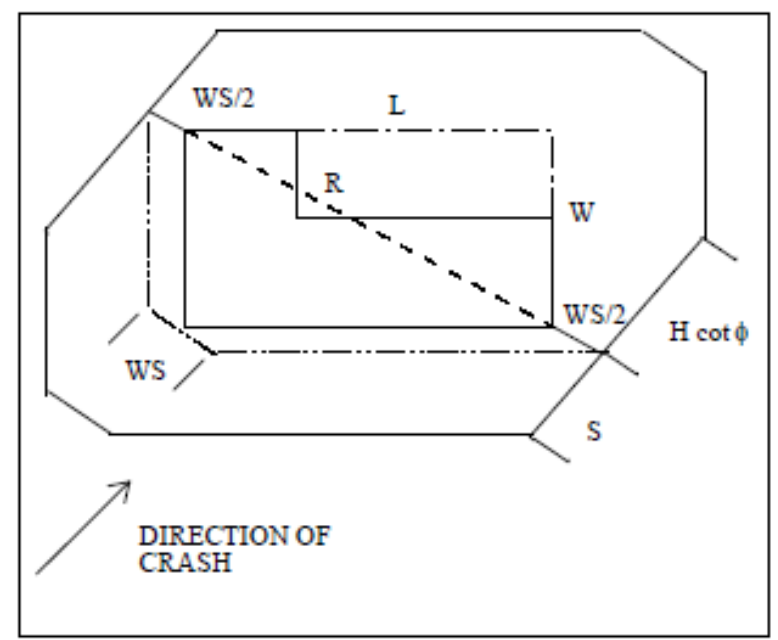

Figure 2 - Rectangular Facility Effective Impact Area per DOE-STD-3014

Per DOE-STD-3014, the equations for the bounding effective impact area of a facility are expressed as follows:

$$
A_{3014, \text { eff }}=A_{3014, F l y-i n}+A_{3014, \text { Skid }}
$$

Where;

$$
A_{3014, F l y-i n}=(W S+R) H \cot (\phi)+\frac{2 \cdot L \cdot W \cdot W S}{R}+(L \cdot W)
$$

And,

$$
A_{3014, \text { Skid }}=(W S+R) \cdot S
$$

Where;

$$
\begin{aligned}
& \mathrm{A}_{3014, \mathrm{eff}}=\text { Effective impact area per DOE-STD-3014 } \\
& \mathrm{A}_{3014, \text { Fly-in }} \quad=\text { Effective fly-in area per DOE-STD-3014 } \\
& \mathrm{A}_{3014 \text {,Skid }}=\text { Effective skid area per DOE-STD-3014 } \\
& \text { WS } \quad=\text { Aircraft wingspan } \\
& \mathrm{R}=\text { Length of the diagonal of the facility, }=\sqrt{L^{2}+W^{2}} \\
& \mathrm{H} \quad=\text { Facility height } \\
& \cot (\theta) \quad=\text { Cotangent of the aircraft impact angle } \\
& \mathrm{L} \quad=\text { Length of facility } \\
& \mathrm{W} \quad \text { = Width of facility }
\end{aligned}
$$

As noted in DOE-STD-3014, the assumptions which support the derivation of Equations 1-3 provide a conservative approximation to the true effective area. 


\subsection{DERIVATION OF RADIALLY-AVERAGED EFFECTIVE IMPACT AREA}

\subsubsection{Application for Instances Where the Value for $\mathbf{N}_{\mathrm{ops}}$ is not Radially-Dependent}

Although proximity to an airport or a designated airway could bias one sector, the direction of flight of an aircraft can be assumed to not be limited to any specific orientation with respect to a structure. In such instances, the direction of aircraft flight with respect to a structure can be assumed to be random and not limited to the conservative single direction that was utilized in the derivation of the DOE-STD-3014 effective impact area. For example, General Aviation (GA) aircraft engaged in non-airport operations* (i.e., the "cruise" phase of flight) typically adhere to point-to-point routes and are not limited to specific designated airways. On the other hand, commercial aviation engaged in non-airport operations are typically limited to designated airways which constrain the direction of flight. As such, an assessment of the GA aircraft "cruise” operations within vicinity of a structure could be considered as directionally random. Conversely, commercial aviation traffic in the vicinity of a structure would generally be characterized as directionally specific.

The elements required to be evaluated are the same as were evaluated for the maximum effective impact area: (i) the skid area, and (ii) the fly-in area. In this case, a derivation of the effective impact area will incorporate the aircraft flight direction in the equation.

For those instances when the direction of flight can be assumed to be random (i.e., not-specific to any direction relative to a structure), a radially-averaged effective impact area can be utilized, which is specified as follows:

$$
A_{e f f}(\theta)_{a v g}=\frac{1}{\theta_{2}-\theta_{1}} \int_{\theta_{1}}^{\theta_{2}} A_{e f f}(\theta) d \theta
$$

Where;

$$
\begin{array}{ll}
\mathrm{A}_{\text {eff }}(\theta) & =\text { Effective impact area at flight direction } \theta \\
\theta_{\mathrm{i}} & =\text { Angle of aircraft flight path relative to a structure }
\end{array}
$$

A solution to Equation 4 requires the specification of the lower integration limit $\left(\theta_{1}\right)$ and the upper integration limit $\left(\theta_{2}\right)$. When the footprint of a structure is modelled as a shape with a minimum of twoaxis symmetry (e.g., rectangle, parallelogram, square, circle), then the effective impact area, $A_{\text {eff }}(\theta)$, is identical when evaluated at its reciprocal, $\mathrm{A}_{\mathrm{eff}}\left(\theta_{\mathrm{rec}}\right)$, where;

$$
\theta_{\text {rec }}=\left\{\begin{array}{c}
\pi+\theta ; \text { for } 0 \leq \theta<\pi \\
2 \pi-\theta ; \text { for } \pi \leq \theta<2 \pi
\end{array}\right.
$$

Therefore, $A_{\text {eff }}(\theta)$ has a symmetry of $\pi / 2$ for shapes with a minimum of two-axis symmetry. For such instances, a solution to the Equation 4 integral can be determined by defining the lower integration limit $\left(\theta_{1}\right)$ as zero and defining the upper integration limit $\left(\theta_{1}\right)$ as $\pi / 2$.

The effective impact area can now be expressed in terms of the radially dependent area elements as follows:

Airport operations are considered to be takeoffs, landings, and flight operations associated with take-offs and landings within the vicinity of an airport. Non-airport operations are typically considered as "cruise" operations. 


$$
A_{\text {eff }}(\theta)=A_{\text {Skid }}(\theta)+A_{F P}+A_{\text {Shadow }}(\theta)
$$

Where;

$$
\begin{array}{ll}
\mathrm{A}_{\text {Skid }}(\theta) & =\text { Skid area when the direction of flight is at } \theta \text { radians } \\
\mathrm{A}_{\mathrm{FP}} & =\text { Footprint of structure } \\
\mathrm{A}_{\text {Shadow }}(\theta) & =\text { Shadow area when the direction of flight is at } \theta \text { radians }
\end{array}
$$

With the exception of the footprint of the structure $\left(\mathrm{A}_{\mathrm{FP}}\right)$, the other aircraft impact area elements in Equation 6 are assumed to be dependent upon the direction of flight of an aircraft relative to a structure.

Substitution of Equation 6 into Equation 4 is expressed as;

$$
A_{\text {eff }}(\theta)_{\text {avg }}=\left(\frac{1}{\theta_{2}-\theta_{1}}\right) \int_{\theta_{1}}^{\theta_{2}}\left(A_{\text {Skid }}(\theta)+A_{F P}+A_{\text {Shadow }}(\theta)\right) d \theta
$$

And upon rearrangement yields,

$$
A_{\text {eff }}(\theta)_{\text {avg }}=\left(\frac{1}{\theta_{2}-\theta_{1}}\right)\left\{\int_{\theta_{1}}^{\theta_{2}} A_{F P} d \theta+\int_{\theta_{1}}^{\theta_{2}} A_{\text {Skid }}(\theta) d \theta+\int_{\theta_{1}}^{\theta_{2}} A_{\text {Shadow }}(\theta) d \theta\right\}
$$

[Eqn. 7]

As noted in Equation 7, the impact area elements can be separately integrated in determining the radially-averaged effective impact area. And as already noted, the footprint of a structure, $A_{\mathrm{FP}}$, is not dependent upon the direction of flight relative to the structure. As such, the integration of the footprint of the structure can be simplified as;

$$
\left(\frac{1}{\theta_{2}-\theta_{1}}\right) \int_{\theta_{1}}^{\theta_{2}} A_{F P} d \theta=A_{F P}
$$

Substitution of Equation 8 into Equation 7 yields;

$$
A_{\text {eff }}(\theta)_{\text {avg }}=A_{F P}+\left(\frac{1}{\theta_{2}-\theta_{1}}\right)\left\{\int_{\theta_{1}}^{\theta_{2}} A_{\text {Skid }}(\theta) d \theta+\int_{\theta_{1}}^{\theta_{2}} A_{\text {Shadow }}(\theta) d \theta\right\}
$$

[Eqn. 9]

Per Equation 9, only the skid area term, $A_{\text {skid }}(\theta)$, and the shadow area term, $A_{\text {shadow }}(\theta)$ are required to be integrated in order to derive the radially-averaged effective impact area.

In addition to the radially-averaged effective impact area, the maximum effective impact area, $\mathrm{A}_{\text {eff }}\left(\theta_{\max }\right)$ can be determine for when the direction of flight corresponds to $\theta_{\max }$. A determination of the value of $\theta_{\max }$ can be made by computing the first derivative of $A_{\text {eff }}(\theta)$. When $A_{\text {eff }}(\theta)=A_{\text {eff }}\left(\theta_{\max }\right)$, the first derivative of $A_{\text {eff }}(\theta)$ is equal to zero, which is expressed as:

$$
\frac{d}{d \theta}\left(A_{\text {eff }}(\theta)\right)=f\left(\theta_{\max }\right)=0
$$


Therefore, $\theta_{\max }$ can be determined by evaluating Equation 10. After determining $\theta_{\max }$, then the maximum effective impact area, $A_{\text {eff }}\left(\theta_{\max }\right)$ can be calculated.

\subsubsection{Application for Instances Where the Value for $\mathbf{N}_{\text {ops }}$ can be Radially-Dependent}

Instances can arise where the flight patterns of aircraft within the vicinity of a structure can be biased. In such instances, the air traffic patterns would not necessarily be equally distributed radially around the structure. When such situations occur, the value for $\operatorname{NPf}(x, y)(\theta)$ is now radially-dependent and must be analyzed accordingly.

A method for handling this type of air traffic pattern behavior involves dividing the area surrounding the structure of interest into radial sectors. The individual sectors can be then be separately addressed to calculate sector specific crash probability, $\mathrm{F}_{\sigma}$. The sector crash probabilities can be summed in order to determine the over crash probability, F;

$$
F=\sum_{\sigma=1}^{\varepsilon}\left(F_{\sigma}\right)
$$

Where;

$$
\begin{array}{ll}
\mathrm{F} & =\text { Total impact probability } \\
\mathrm{F}_{\sigma} & =\text { Impact probability associated with sector } \sigma \\
\varepsilon & =\text { Total number of sectors }
\end{array}
$$

\begin{tabular}{|c|c|c|}
\hline \multicolumn{3}{|c|}{$\frac{\text { Analytical Elements for Calculating the Probability o }}{\text { an Aircraft Impact on a Per Sector Basis }}$} \\
\hline Sector & $\begin{array}{l}\text { Fraction of total air } \\
\left.\text { traffic ( } \mathrm{N}_{\mathrm{ops}}\right) \\
\text { assigned to Sector }\end{array}$ & $\begin{array}{l}\text { Radially-Avg'd } \\
\text { Effective Impact } \\
\text { Area of Sector }\end{array}$ \\
\hline 1 & $\gamma_{\mathrm{N} 1}$ & $A_{\text {eff }}(\theta)_{\text {avg }, 1}$ \\
\hline 2 & $\gamma_{\mathrm{N} 2}$ & $A_{\text {eff }}(\theta)_{\text {avg }, 2}$ \\
\hline 3 & $\gamma_{\mathrm{N} 3}$ & $A_{\text {eff }}(\theta)_{\text {avg }, 3}$ \\
\hline 4 & $\gamma_{\mathrm{N} 4}$ & $A_{\text {eff }}(\theta)_{\text {avg }, 4}$ \\
\hline 5 & $\gamma_{\mathrm{N} 5}$ & $A_{\text {eff }}(\theta)_{\text {avg }, 5}$ \\
\hline 6 & $\gamma_{\mathrm{N} 6}$ & $A_{\text {eff }}(\theta)_{\text {avg }, 6}$ \\
\hline 7 & $\gamma_{\mathrm{N} 7}$ & $A_{\text {eff }}(\theta)_{\text {avg }, 7}$ \\
\hline 8 & $\gamma_{\mathrm{N} 8}$ & $A_{\text {eff }}(\theta)_{\text {avg }, 8}$ \\
\hline \multicolumn{3}{|l|}{ Note: } \\
\hline \multicolumn{3}{|c|}{$\sum \gamma_{N i}=1$} \\
\hline \multicolumn{3}{|c|}{$\frac{1}{\varepsilon} \cdot \sum A_{e f f}(\theta)_{a v g, \sigma}=A_{e f f}(\theta)_{a v g}$} \\
\hline
\end{tabular}

Figure 3 illustrates an example of how to divide the area around a structure into sectors which then can be analyzed for determining the sector specific impact probability.

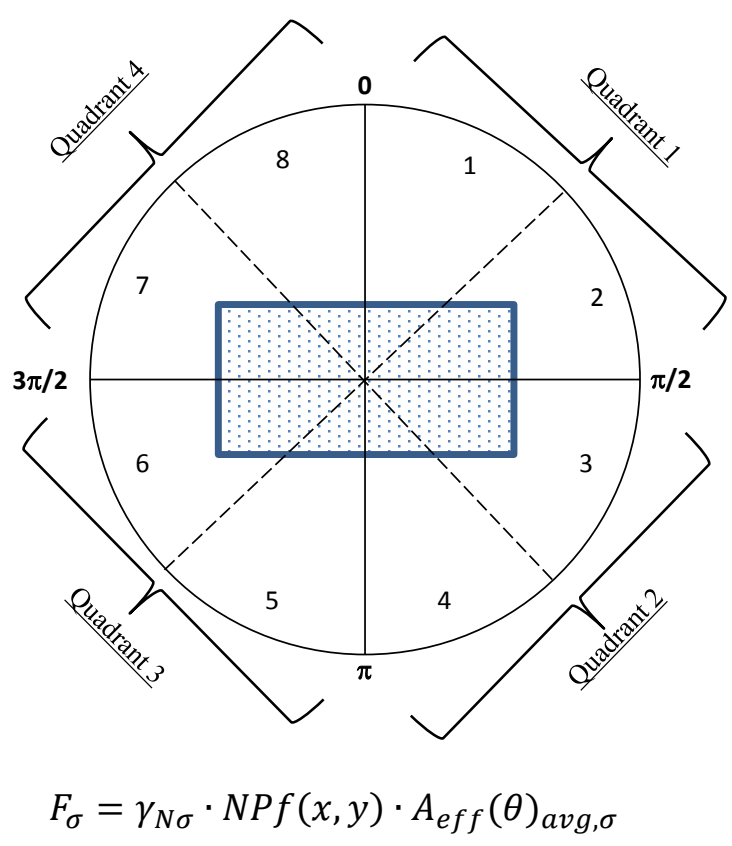

Figure 3 - Illustration of Analyzing Aircraft Crash Impact Probability per Sector 
The determination of crash probability for a specific sector is based on the following equation:

$$
F_{\sigma}=\gamma_{N \sigma} \cdot N P f(x, y) \cdot A_{e f f}(\theta)_{a v g, \sigma}
$$

Where;

$$
\begin{array}{ll}
\gamma_{N \sigma} & =\text { Fraction of total air traffic assigned to Sector } \sigma \\
N P f(x, y) & \left.=\text { Aircraft crash density factor; [crashes } / \mathrm{yr} / \mathrm{mi}^{2}\right] \\
A_{\text {eff }}(\theta)_{\text {avg, } \sigma} & =\text { Radially-averaged effective impact area for sector } \sigma ;\left[\mathrm{mi}^{2}\right]
\end{array}
$$

As observed in Equation 12, the use of a radially-averaged effective impact area is a useful concept in analyzing the crash probability for each sector. In the previous section, the radially-averaged effective impact area was determined by integrating the radially-dependent effective area equation from $0 \leq \theta \leq$ $\pi / 2$. When conducting a sector analysis, the general form of the integration equation (Equation 4 ) is appropriate for determining the radially-averaged effective impact area of the sector. 


\section{DISCUSSION OF RESULTS}

\subsection{EFFECTIVE IMPACT AREA EQUATIONS}

Using the methodology outlined in Section 2.2 of this report, the following effective impact area attributes were derived as detailed in Appendix A of this report:

(i) the radially-dependent effective impact area (Equation 13),

(ii) the radially-averaged effective impact area (Equation 14), and

(iii) the direction of flight into a structure that corresponds to the maximum effective impact area (Equation 15).

$$
\begin{aligned}
& A_{e f f}(\theta)=(L \cdot W)+\left[\begin{array}{c}
(S+H \cot (\phi))(W S+W \cdot \sin (\theta)+L \cdot \cos (\theta)) \\
+W S(W \cdot \cos (\theta)+L \cdot \sin (\theta))
\end{array}\right] \\
& A_{\text {eff }}(\theta)_{\text {avg }}=(L \cdot W)+\left(\frac{2}{\pi}\right)\left[(S+H \cot (\phi))\left(\left(\frac{\pi}{2}\right) W S+W+L\right)+W S(W+L)\right] \\
& \theta_{\text {max }}=\arctan \left[\frac{\left(\frac{S+H \cot (\phi)}{W S}\right) \cdot\left(\frac{W}{L}\right)+1}{\left(\frac{W}{L}\right)+\left(\frac{S+H \cot (\phi)}{W S}\right)}\right]
\end{aligned}
$$

[Eqn. 15]

\subsection{USAGE EXAMPLE}

The following example evaluates the effective impact area for a fictional 75 -ft wide by 250 - $\mathrm{ft}$ long, threestory tall (30-ft) rectangular building. The aircraft data is based on general aviation data from Table B-16, Table B-17, and Table B-18 of DOE-STD-3014. The input data is summarized in Table 1.

\begin{tabular}{|l|l|l|l|}
\hline \begin{tabular}{|} 
Table 1 - Structure and Aircraft Parameters \\
For Example Calculation
\end{tabular} \\
\hline Attribute & Symbol & Value & Units \\
\hline \multicolumn{4}{|c|}{ Structure Data } \\
\hline Width & W & 75 & $\mathrm{ft}$ \\
\hline Length & L & 250 & $\mathrm{ft}$ \\
\hline Height & H & 30 & $\mathrm{ft}$ \\
\hline \multicolumn{4}{|c|}{ Aircraft Data } \\
\hline Skid & S & 60 & $\mathrm{ft}$ \\
\hline Wing Span & WS & 50 & $\mathrm{ft}$ \\
\hline Mean $\cot \phi$ & $\cot (\phi)$ & 8.2 & -- \\
\hline
\end{tabular}

Using the input data specified in Table 1, the calculated effective area attributes for the example structure are reported in Table 2 and graphically illustrated in Figure 4. 


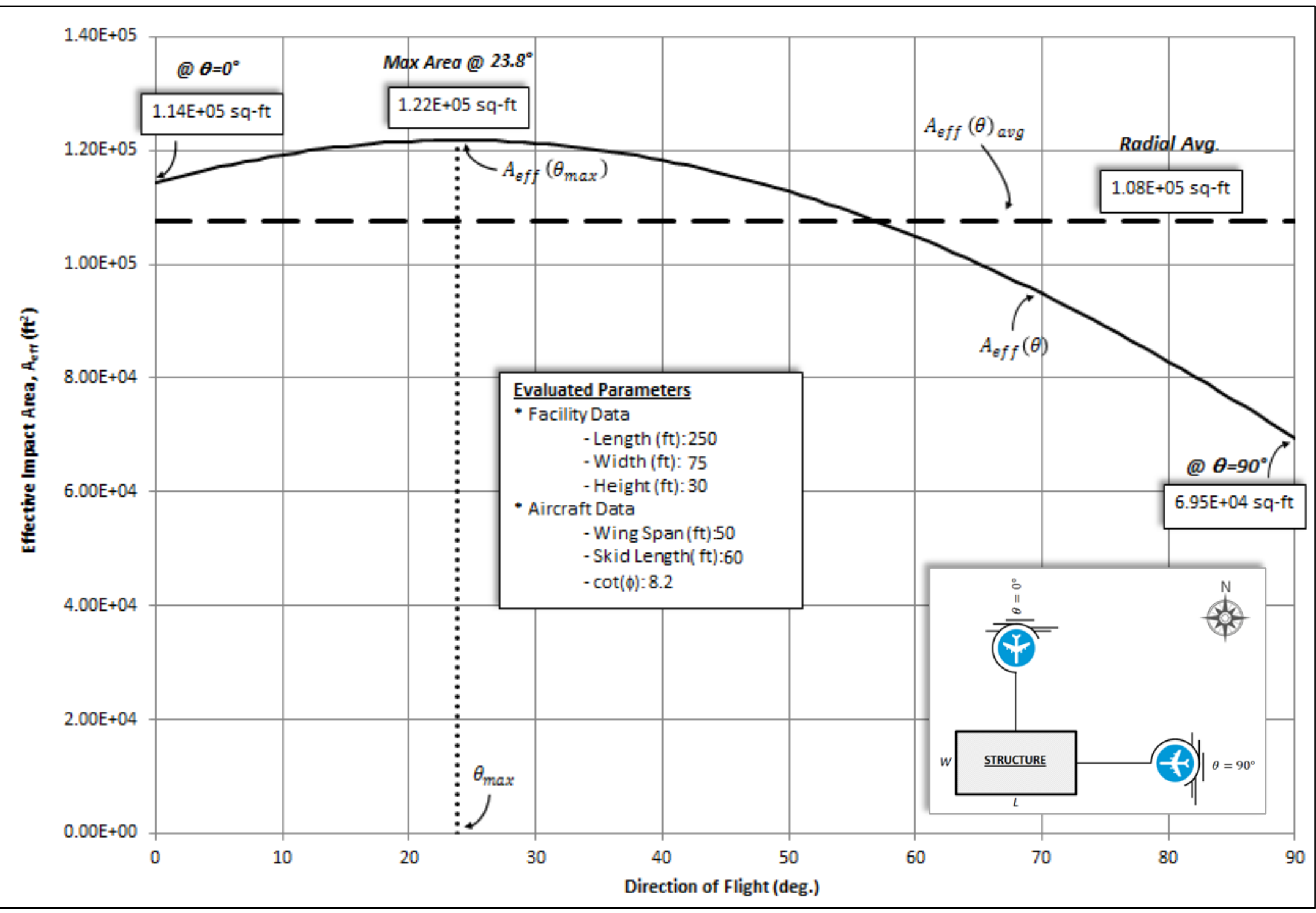

Figure 4 - Example Graphical Representation of Radially-Averaged Effective Impact Area 


\begin{tabular}{|l|c|c|c|}
\hline \multicolumn{4}{|c|}{ Table 2 - Calculated Effective Impact Area Attributes for an Example Structure } \\
\hline \multicolumn{1}{|c|}{ Attribute } & Symbol & Value & Units \\
\hline Effective Impact Area @ $\theta=0^{\circ}$ & $\mathrm{A}_{\text {eff }}\left(0^{\circ}\right)$ & $1.14 \mathrm{E}+05$ & $\mathrm{ft}^{2}$ \\
\hline Maximum Effective Impact Area & $\mathrm{A}_{\mathrm{eff}}\left(\theta_{\max }\right)$ & $1.22 \mathrm{E}+05$ & $\mathrm{ft}^{2}$ \\
\hline Radially-Averaged Effective Impact Area & $\mathrm{A}_{\text {eff }}(\theta)_{\mathrm{avg}}$ & $1.08 \mathrm{E}+05$ & $\mathrm{ft}^{2}$ \\
\hline Effective Impact Area @ $\theta=90^{\circ}$ & $\mathrm{A}_{\mathrm{eff}}\left(90^{\circ}\right)$ & $6.95 \mathrm{E}+05$ & $\mathrm{ft}^{2}$ \\
\hline
\end{tabular}

As previously discussed, the calculation of $\mathrm{A}_{\mathrm{eff}}$ per DOE-STD-3014 is based a direction of flight which corresponds to a conservatively derived effective impact area, $\theta_{\max }$. However, under the premise that the direction of flight is not limited to any single heading, then the use of a radially-averaged effective impact area value is appropriate. As noted in Table 2, the radially-averaged effective impact area is $11.56 \%$ lower than the maximum effective impact area. As such, the use of a radially-averaged effective impact area will result in a commensurate decrease in the calculated aircraft impact probability of equal magnitude.

\subsection{COMPARISON TO DOE-STD-3014 EFFECTIVE IMPACT AREA}

Using the methodology outlined in this report, the maximum effective impact area can be determined by first calculating the direction of flight that corresponds to the maximum effective impact area using Equation 13. Once a value for $\theta_{\max }$ is determined, it is used as an input into Equation 13 to determine the maximum effective impact area, $A_{\text {eff }}\left(\theta_{\max }\right)$. The calculation of $\theta_{\max }$ is of interest since it allows for an assessment of the validity of the following statement in DOE-STD-3014: ${ }^{\dagger}$

“...To calculate the effective area, assume that the aircraft skids or flies into the structure in the direction that produces the largest area, i.e., crashing in a direction perpendicular to the largest diagonal of the building. ..."

As illustrated in Figure 5, the direction of flight is perpendicular to the diagonal of a structure in accordance with the following equation:

$$
\theta_{\text {diag }}=\arctan \left(\frac{W}{L}\right)
$$

Table 3 provides ten example cases involving varying structure dimensions and aircraft impact parameters, allowing for a calculation of $\theta_{\max }$ using Equation 15 and $\theta_{\text {diag }}$ using Equation 16 . Also, these ten test cases allow for a comparison of the maximum effective impact areas using Equation 2 and Equation 3 to determine $A_{3014, \text { eff }}$ and using Equation 13 to determine $A_{\text {eff }}\left(\theta_{\text {max }}\right)$.

As noted in Table 3, value for $A_{\text {eff }}\left(\theta_{\max }\right)$ is slightly larger than $A_{3014, \text { eff }}$ except when the footprint for a structure is geometrically defined as a square (i.e., $\mathrm{L}=\mathrm{W}$ ) (Cases $5-7$ ). This observation is supported by proof in Figure 6 which demonstrates that the maximum effective impact area only occurs perpendicular to the diagonal when the either (i) $\mathrm{W}=\mathrm{L}$ (i.e., the footprint of the structure is geometrically defined as a square), or (ii) the value for $\left(\frac{S+H \cot \phi}{W S}\right)$ approaches infinity.

$\dagger \quad$ Page 41 of DOE-STD-3014-2006 


\begin{tabular}{|c|c|c|c|c|c|c|c|c|c|c|c|c|c|}
\hline \multicolumn{14}{|c|}{ Table 3 - Comparison of $A_{\text {eff }}\left(\theta_{\max }\right)$ and $A_{3014, \text { eff }}$} \\
\hline & \multicolumn{3}{|c|}{ Structure Data } & \multicolumn{3}{|c|}{ Aircraft Data } & \multicolumn{4}{|c|}{ Radially-Dependent Effective Area Calc. } & \multicolumn{2}{|c|}{3014 Calc. } & \multirow[b]{2}{*}{$\begin{array}{c}\Delta \mathbf{A}_{\text {eff }} \\
(\%)\end{array}$} \\
\hline Case & $\begin{array}{l}\text { Width } \\
\text { (ft) }\end{array}$ & $\begin{array}{c}\text { Length } \\
\text { (ft) }\end{array}$ & $\begin{array}{c}\text { Height } \\
\text { (ft) }\end{array}$ & $\begin{array}{c}\text { Skid } \\
\text { (ft) }\end{array}$ & $\begin{array}{c}\text { Wing } \\
\text { Span (ft) }\end{array}$ & $\begin{array}{c}\text { Mean } \\
\cot \phi\end{array}$ & W/L & $\frac{(\mathrm{S}+\mathrm{H} \cot \phi)}{\mathrm{WS}}$ & $\begin{array}{c}\theta_{\max } \\
\text { (deg.) }\end{array}$ & $\begin{array}{c}\mathbf{A}_{\text {eff }}\left(\theta_{\max }\right) \\
\left(\mathbf{f t}^{2}\right)\end{array}$ & $\begin{array}{c}A_{3014, \text { eff }} \\
\left(\mathrm{ft}^{2}\right)\end{array}$ & $\begin{array}{c}\theta_{\text {diag }} \\
\text { (deg.) }\end{array}$ & \\
\hline 1 & 100 & 200 & 50 & 60 & 50 & 8.2 & 0.5 & 9.4 & 29.9 & $1.58 \mathrm{E}+05$ & $1.58 \mathrm{E}+05$ & 26.6 & $0.13 \%$ \\
\hline 2 & 100 & 200 & 30 & 60 & 50 & 8.2 & 0.5 & 6.12 & 31.5 & $1.13 \mathrm{E}+05$ & $1.13 \mathrm{E}+05$ & 26.6 & $0.26 \%$ \\
\hline 3 & 100 & 200 & 10 & 30 & 50 & 8.2 & 0.5 & 2.24 & 37.7 & $6.02 \mathrm{E}+04$ & $5.96 \mathrm{E}+04$ & 26.6 & $1.10 \%$ \\
\hline 4 & 100 & 200 & 30 & 0 & 50 & 8.2 & 0.5 & 4.92 & 32.6 & $9.66 \mathrm{E}+04$ & $9.63 \mathrm{E}+04$ & 26.6 & $0.36 \%$ \\
\hline 5 & 100 & 100 & 30 & 60 & 50 & 8.2 & 1 & 6.12 & 45.0 & $7.56 \mathrm{E}+04$ & $7.56 \mathrm{E}+04$ & 45.0 & $0.00 \%$ \\
\hline 6 & 100 & 100 & 30 & 30 & 50 & 8.2 & 1 & 5.52 & 45.0 & $6.99 \mathrm{E}+04$ & $6.99 \mathrm{E}+04$ & 45.0 & $0.00 \%$ \\
\hline 7 & 100 & 100 & 30 & 0 & 50 & 8.2 & 1 & 4.92 & 45.0 & $6.42 \mathrm{E}+04$ & $6.42 \mathrm{E}+04$ & 45.0 & $0.00 \%$ \\
\hline 8 & 200 & 100 & 30 & 60 & 50 & 8.2 & 2 & 6.12 & 58.5 & $1.13 \mathrm{E}+05$ & $1.13 \mathrm{E}+05$ & 63.4 & $0.26 \%$ \\
\hline 9 & 200 & 100 & 30 & 60 & 50 & 4.1 & 2 & 3.66 & 55.8 & $7.95 \mathrm{E}+04$ & $7.90 \mathrm{E}+04$ & 63.4 & $0.57 \%$ \\
\hline 10 & 200 & 100 & 30 & 60 & 50 & 2.05 & 2 & 2.43 & 52.9 & $6.28 \mathrm{E}+04$ & $6.22 \mathrm{E}+04$ & 63.4 & $0.99 \%$ \\
\hline
\end{tabular}




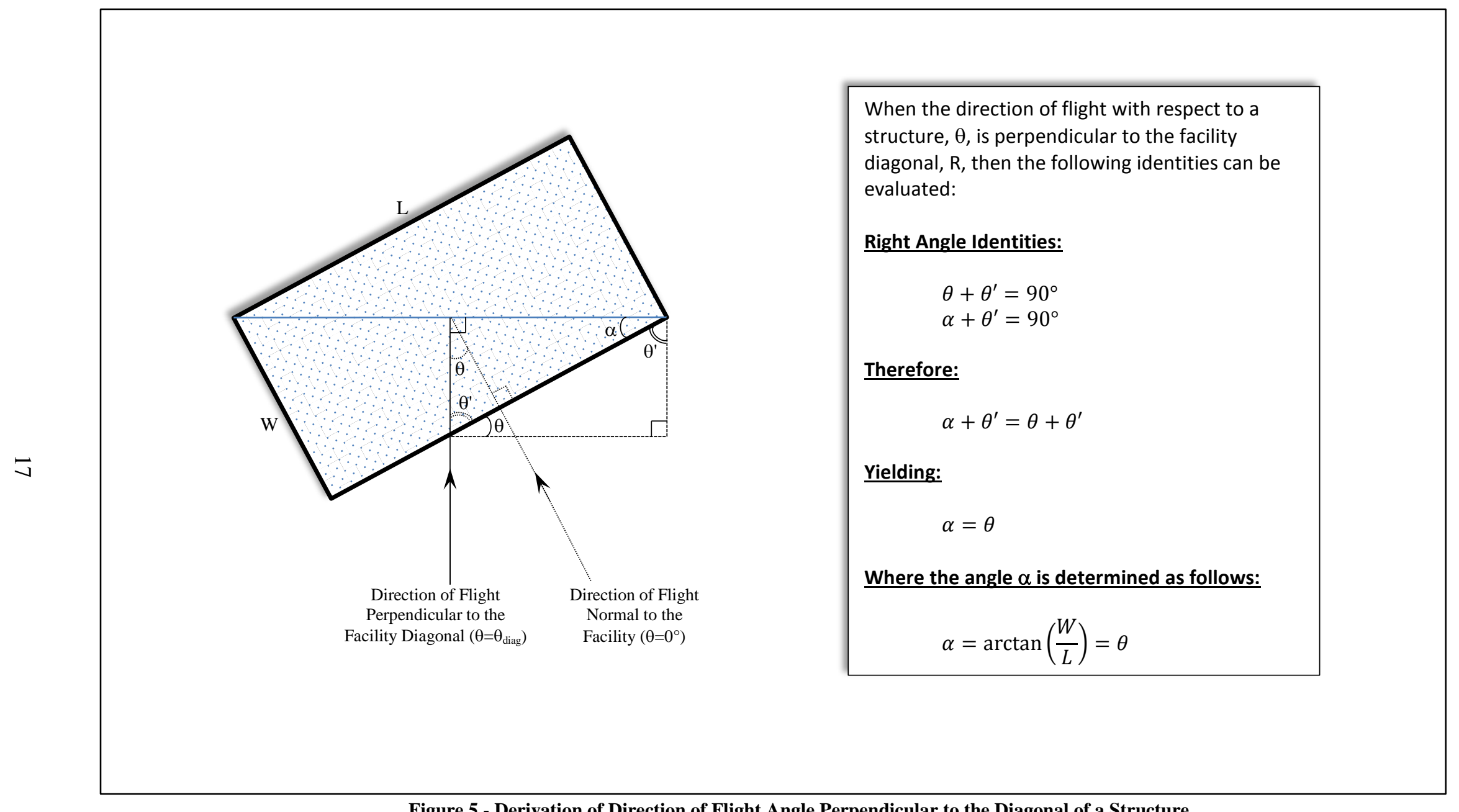

Figure 5 - Derivation of Direction of Flight Angle Perpendicular to the Diagonal of a Structure 
As defined by Equation 15 and Equation 16:

$$
\theta_{\text {max }}=\arctan \left[\frac{\left(\frac{S+H \cot \phi}{W S}\right) \cdot\left(\frac{W}{L}\right)+1}{\left(\frac{W}{L}\right)+\left(\frac{S+H \cot \phi}{W S}\right)}\right] \quad \text { and } \quad \theta_{\text {diag }}=\arctan \left[\frac{W}{L}\right]
$$

Under the condition where $\theta_{\max }=0_{\text {diag, }}$ the following relationship exists:

$$
\left[\frac{\left(\frac{S+H \cot \phi}{W S}\right) \cdot\left(\frac{W}{L}\right)+1}{\left(\frac{W}{L}\right)+\left(\frac{S+H \cot \phi}{W S}\right)}\right]=\left(\frac{W}{L}\right)
$$

\section{Re-arrangement yields:}

$$
\begin{aligned}
& \left(\frac{S+H \cot \phi}{W S}\right) \cdot\left(\frac{W}{L}\right)+1=\left(\frac{W}{L}\right)^{2}+\left(\frac{S+H \cot \phi}{W S}\right) \cdot\left(\frac{W}{L}\right) \\
& \left(\frac{W}{L}\right)^{2}-1=0 \\
& \frac{W}{L}=1
\end{aligned}
$$

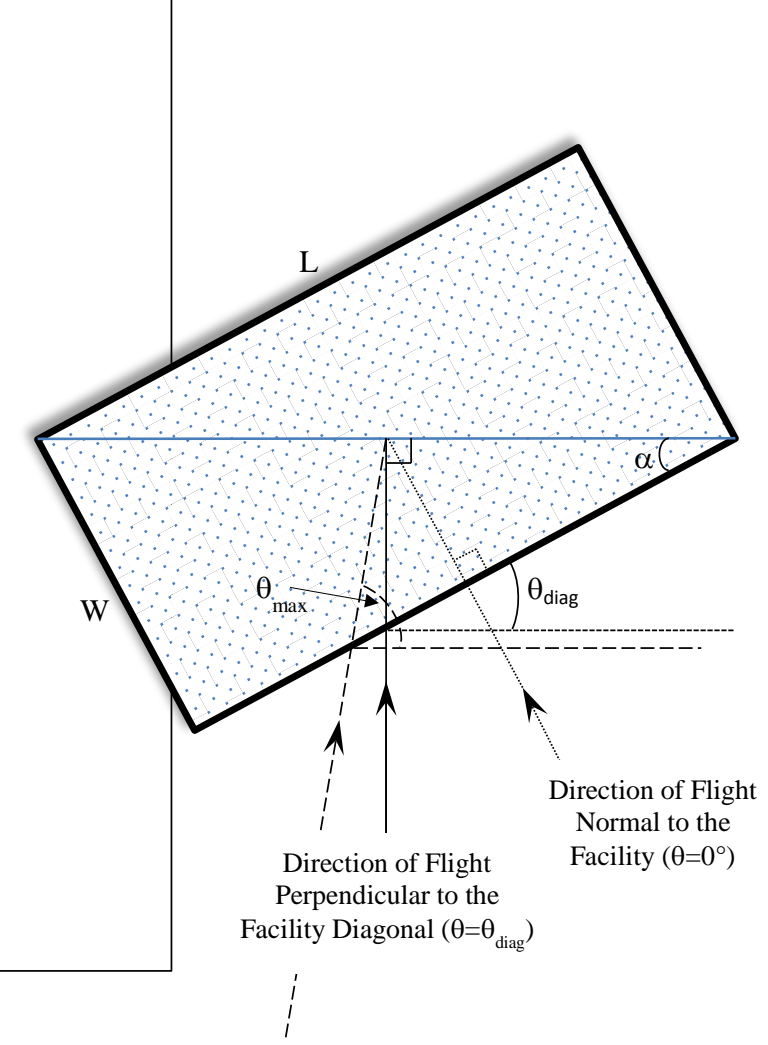




\subsection{SECTOR SPECIFIC CALCULATIONS}

The performance of a sector-based analysis of an impact probability calculation requires the ability to specify sector-specific aircraft flight traffic and a determination of the radially-averaged effective impact area for the sector. As demonstrated in Section 2, the calculation of the radially-averaged effective impact area only requires an evaluation of the Equation 4 integral. A specification of the sector-specific aircraft flight traffic factor, $\gamma_{\mathrm{N} \sigma}$, would require access to flight pattern data or at least a method to estimate the flight pattern distribution. The methodology and inputs associated with the derivation of $\gamma_{\mathrm{N} \sigma}$ are outside the scope of this report. For example purposes, values of $\gamma_{\mathrm{N} \sigma}$ provided in the following examples are arbitrary and solely used for the purpose of demonstrating how to conduct a sector-based impact probability analysis.

In the first example, the facility from Section 3.2 is assumed to be divided into 8 sectors ( 2 sectors per quadrant), similar to the illustration in Figure 3. The air traffic is assumed to equally distributed amongst all eight sectors, therefore $\gamma_{\mathrm{N} \sigma}=0.125$ for each sector. The average CONUS value from Table B-14 of DOE-STD-3014 will be used for the aircraft crash density NPf(x,y) = 2E-4 crashes $/ \mathrm{mi}^{2} / \mathrm{yr}$. The results are tabulated in Table 4.

Table 4 - Sector-Based Calculation for Equally Distributed Air Traffic Patterns Around A Structure

\begin{tabular}{|c|c|c|c|c|}
\hline Quadrant & Sector & $\gamma_{\mathrm{N \sigma}}$ & $\begin{array}{c}\mathbf{A}_{\text {eff }}(\theta)_{\text {avg }, \sigma} \\
\left(\mathbf{f t}^{2}\right)\end{array}$ & $\begin{array}{c}\mathbf{F}_{\sigma} \\
\text { (crashes/yr) }\end{array}$ \\
\hline $\mathrm{I}$ & 1 & 0.125 & $1.20 \mathrm{E}+05$ & $1.07 \mathrm{E}-07$ \\
\hline I & 2 & 0.125 & $9.59 E+04$ & 8.60E-08 \\
\hline II & 3 & 0.125 & $9.59 E+04$ & 8.60E-08 \\
\hline II & 4 & 0.125 & $1.20 \mathrm{E}+05$ & $1.07 \mathrm{E}-07$ \\
\hline III & 5 & 0.125 & $1.20 \mathrm{E}+05$ & 1.07E-07 \\
\hline III & 6 & 0.125 & $9.59 \mathrm{E}+04$ & 8.60E-08 \\
\hline IV & 7 & 0.125 & $9.59 E+04$ & 8.60E-08 \\
\hline \multirow[t]{3}{*}{ IV } & 8 & 0.125 & $1.20 \mathrm{E}+05$ & 1.07E-07 \\
\hline & & $A_{\text {eff }}(\theta)_{\text {avg }}$ & $1.08 \mathrm{E}+05$ & \\
\hline & & & $\mathbf{F}_{\mathrm{TOT}}$ & 7.73E-07 \\
\hline
\end{tabular}

Several observations can be made of the sector specific calculations in Table 4. First, the average of the eight sector specific radially-averaged effective impact areas equals is equal to the overall radiallyaveraged effective impact area, $A_{\text {eff }}(\theta)_{\text {avg }}=1.08 \mathrm{E}+05 \mathrm{ft}^{2}$. This is the same value as would be calculated directly using Equation 14, as noted in Figure 4. Second, the total impact probability, $\mathrm{F}_{\text {Tот, }}$, is the sum of the individual sector specific impact probabilities, 7.73E-07 $\mathrm{yr}^{-1}$. Since the air traffic was assumed to be equally distributed amongst all eight sectors, the total impact probability derived in Table 4 could also have been directly calculated using the equation from DOE-STD-3014:

$$
F=[N P f(x, y)] \cdot A_{e f f}(\theta)_{\text {avg }}=\frac{\left(2 E-4 \frac{\text { crashes }}{m i^{2} \cdot y r}\right) \cdot\left(1.08 E+05 f t^{2}\right)}{\left(5280 \frac{f t}{m i}\right)^{2}}=7.73 E-07 y r^{-1}
$$

In a second example, the air traffic is assumed to be limited to flight paths which transit in an East-West pattern (Sectors 2, 3, 6, and 7), with no air traffic flight paths associated with a North-South pattern (Sectors 1,4,5, and 8). Again, an average CONUS value from Table B-14 of DOE-STD-3014 will be used for the aircraft crash density; $\operatorname{NPf}(\mathrm{x}, \mathrm{y})=2 \mathrm{E}-4$ crashes $/ \mathrm{mi}^{2} / \mathrm{y}$. The results are tabulated in Table 5 . 
Table 5 - Sector-Based Calculation for an East-West Distributed Air Traffic Pattern Around A Structure

\begin{tabular}{|c|c|c|c|c|}
\hline Quadrant & Sector & $\gamma_{\mathrm{N} \sigma}$ & $\begin{array}{c}\mathbf{A}_{\text {eff }}(\theta)_{\text {avg }, \sigma} \\
\left(\mathbf{f t}^{2}\right)\end{array}$ & $\begin{array}{c}\mathbf{F}_{\sigma} \\
\text { (crashes/yr) }\end{array}$ \\
\hline $\mathrm{I}$ & 1 & -- & $1.20 \mathrm{E}+05$ & -- \\
\hline I & 2 & 0.25 & $9.59 \mathrm{E}+04$ & $1.72 \mathrm{E}-07$ \\
\hline II & 3 & 0.25 & $9.59 \mathrm{E}+04$ & $1.72 \mathrm{E}-07$ \\
\hline II & 4 & -- & $1.20 \mathrm{E}+05$ & -- \\
\hline III & 5 & -- & $1.20 \mathrm{E}+05$ & -- \\
\hline III & 6 & 0.25 & $9.59 \mathrm{E}+04$ & $1.72 \mathrm{E}-07$ \\
\hline IV & 7 & 0.25 & $9.59 \mathrm{E}+04$ & $1.72 \mathrm{E}-07$ \\
\hline \multirow[t]{3}{*}{ IV } & 8 & -- & $1.20 \mathrm{E}+05$ & -- \\
\hline & & $\mathbf{A}_{\mathrm{eff}}(\theta)_{\mathrm{avg}}$ & $1.08 \mathrm{E}+05$ & \\
\hline & & & $\mathbf{F}_{\text {TOT }}$ & 6.88E-07 \\
\hline
\end{tabular}

As noted in Table 5, by arbitrarily restricting the flight paths to an East-West pattern, the resulting aircraft impact probability is lower since the air traffic traverses over sectors with lower sector-specific radiallyaveraged effective impact areas than would be incurred in a North-South flight pattern. A confirmation of this effect can be illustrated in a third example where the air traffic is assumed to be limited to flight paths which transit in a North-South pattern (Sectors 1, 4, 5, and 8), with no air traffic flight paths associated with an East-West pattern (Sectors 2,3,6, and 7). Again, an average CONUS value from Table B-14 of DOE-STD-3014 will be used for the aircraft crash density; NPf(x,y) = 2E-4 crashes $/ \mathrm{mi}^{2} / \mathrm{y}$. The results are tabulated in Table 6.

Table 6 - Sector-Based Calculation for a North-South Distributed Air Traffic Pattern Around A Structure

\begin{tabular}{|c|c|c|c|c|}
\hline Quadrant & Sector & $\gamma_{\mathrm{N} \sigma}$ & $\begin{array}{c}A_{\text {eff }}(\theta)_{\text {avg, } \sigma} \\
\left(f^{2} t^{2}\right)\end{array}$ & $\begin{array}{c}\mathbf{F}_{\sigma} \\
\text { (crashes/yr) }\end{array}$ \\
\hline I & 1 & 0.25 & $1.20 \mathrm{E}+05$ & $2.14 \mathrm{E}-07$ \\
\hline I & 2 & -- & $9.59 \mathrm{E}+04$ & -- \\
\hline II & 3 & -- & $9.59 \mathrm{E}+04$ & -- \\
\hline II & 4 & 0.25 & $1.20 \mathrm{E}+05$ & 2.14E-07 \\
\hline III & 5 & 0.25 & $1.20 \mathrm{E}+05$ & $2.14 \mathrm{E}-07$ \\
\hline III & 6 & -- & $9.59 \mathrm{E}+04$ & -- \\
\hline IV & 7 & -- & $9.59 \mathrm{E}+04$ & -- \\
\hline \multirow[t]{3}{*}{ IV } & 8 & 0.25 & $1.20 \mathrm{E}+05$ & $2.14 \mathrm{E}-07$ \\
\hline & & $A_{\text {eff }}(\theta)_{\text {avg }}$ & $1.08 E+05$ & \\
\hline & & & $\mathbf{F}_{\text {TOT }}$ & 8.57E-07 \\
\hline
\end{tabular}

In a fourth and final example, one sector is assumed to have the impact flight path completely obstructed. Examples of this type of obstruction would be a nearby structure which is taller than the target structure, effectively blocking the target structure. Such an obstruction would make the effective impact area for the associated sector equal to zero. In this example, a nearby structure is assumed to completely block the impact flight path of an aircraft for sectors 5 and 6 . The air traffic is assumed to equally distributed amongst all eight sectors. And an average CONUS value from Table B-14 of DOE-STD-3014 will be used for the aircraft crash density; $\operatorname{NPf}(\mathrm{x}, \mathrm{y})=2 \mathrm{E}-4 \mathrm{crashes} / \mathrm{mi}^{2} / \mathrm{y}$. The results are tabulated in Table 7 . 
Table 7 - Sector-Based Calculation for Equally Distributed Air Traffic Patterns Around A Structure With Sectors 5 and 6

\begin{tabular}{|c|c|c|c|c|}
\hline \multicolumn{5}{|c|}{ Obstructed } \\
\hline Quadrant & Sector & $\gamma_{\mathrm{N \sigma}}$ & $\begin{array}{c}\mathbf{A}_{\text {eff }}(\boldsymbol{\theta})_{\text {avg, } \sigma} \\
\left(\mathbf{f t}^{2}\right)\end{array}$ & $\begin{array}{c}\mathbf{F}_{\sigma} \\
\text { (crashes/yr) }\end{array}$ \\
\hline $\mathrm{I}$ & 1 & 0.125 & $1.20 \mathrm{E}+05$ & $1.07 \mathrm{E}-07$ \\
\hline I & 2 & 0.125 & $9.59 \mathrm{E}+04$ & 8.60E-08 \\
\hline II & 3 & 0.125 & $9.59 \mathrm{E}+04$ & 8.60E-08 \\
\hline II & 4 & 0.125 & $1.20 \mathrm{E}+05$ & 1.07E-07 \\
\hline III & 5 & 0.125 & -- & -- \\
\hline III & 6 & 0.125 & -- & -- \\
\hline IV & 7 & 0.125 & $9.59 \mathrm{E}+04$ & 8.60E-08 \\
\hline IV & 8 & 0.125 & $1.20 \mathrm{E}+05$ & $1.07 \mathrm{E}-07$ \\
\hline & & & $\mathbf{F}_{\text {TOT }}$ & 5.80E-07 \\
\hline
\end{tabular}




\section{CONCLUSIONS}

The methodology in this report has demonstrated a viable technique for defining and calculating the following effective impact area attributes for a structure with a footprint defined geometrically as a rectangle:

- Radially-dependent effective impact area, $\mathrm{A}_{\text {eff }}(\theta)$

- Radially-averaged effective impact area, $\mathrm{A}_{\mathrm{eff}}(\theta)_{\mathrm{avg}}$

- The direction of flight relative to a structure which corresponds to the maximum effective impact area, $\theta_{\max }$.

The use of a radially-averaged effective impact area is appropriate for use in a DOE-STD-3014 aircraft crash probability analysis when the direction of flight of an aircraft relative to a structure is justified as random (not specific to any particular direction).

An analysis of the direction of flight which results in the maximum effective impact area, $\theta_{\max }$, does not necessarily correspond to the direction of flight perpendicular to the diagonal of a structure, $\theta_{\text {diag }}$ as declared by DOE-STD-3014. The only instances where $\theta_{\max }=\theta_{\text {diag }}$ occur when: (i) a structure has a footprint defined geometrically as a square $(\mathrm{L}=\mathrm{W})$, or (ii) the value for $\left(\frac{S+H \cot \phi}{W S}\right)$ is very large $\left(>>10^{3}\right)$.

Finally, a sector-based analysis can be performed when the sector specific flight data is available. A radially-averaged effective impact area can be calculated specific to the sector. The sector-specific input data can then be used to calculate an aircraft impact probability for the sector. This type of analysis can be used to account for variations in the number of aircraft operations for each sector. Additionally, this type of analysis can be used for estimating the effects of a co-located structure which can be regarded as an obstruction to a potential aircraft impact event. 


\section{REFERENCES}

1. U. S. Department of Energy. Accident Analysis For Aircraft Crash Into Hazardous Facilities. May 2006. DOE-STD-3014-2006. 
(This page intentionally blank) 
APPENDIX A. DERIVATION OF RADIALLY-AVERAGED EFFECTIVE IMPACT AREA EQUATIONS 
(This page intentionally blank) 


\section{APPENDIX A. DERIVATION OF RADIALLY-AVERAGED EFFECTIVE IMPACT AREA EQUATIONS}

\section{A.1 METHOD 1: A GEOMETRIC ANALYSIS OF EFFECTIVE IMPACT AREA ELEMENTS}

\section{A.1.1 Derivation of Effective Impact Area Equation}

\section{Structure Footprint}

The area occupied by the footprint of a structure is defined by (i) rectangle I, in Figure A-1, with dimensions of L (length) and W (width). The footprint area is calculated as follows:

$$
A_{F P}=L \cdot W
$$

As expected, the footprint area of a structure is independent of an aircraft's direction of flight.

Derivation of Skid Area

The skid area of a rectangular shaped structure is defined in Figure A-1 by (i) rectangle II, and (ii) parallelograms III, IV, V, and VI. ${ }^{\ddagger}$

\begin{tabular}{|c|c|l|l|}
\hline \multicolumn{4}{|c|}{ Table A.1 - Skid Area: Rectangle and Parallelogram Elements } \\
\hline Area & Base & Height & \multicolumn{1}{c|}{ Area Equation } \\
\hline II & $\mathrm{S}$ & $\mathrm{WS}$ & $A_{I I}=S \cdot W S$ \\
\hline III & $\mathrm{S}$ & $\mathrm{W} \sin (\theta)$ & $A_{I I I}=S \cdot W \cdot \sin (\theta)$ \\
\hline IV & $\mathrm{S}$ & $\mathrm{L} \cos (\theta)$ & $A_{I V}=S \cdot L \cdot \cos (\theta)$ \\
\hline V & $\mathrm{W}$ & $0.5 \mathrm{WS} \cos (\theta)$ & $A_{V}=W \cdot 0.5 W S \cdot \cos (\theta)$ \\
\hline VI & $\mathrm{L}$ & $0.5 \mathrm{WS} \sin (\theta)$ & $A_{V I}=L \cdot 0.5 W S \cdot \sin (\theta)$ \\
\hline
\end{tabular}

The total skid area is expressed as follows:

$$
\begin{aligned}
& A_{\text {Skid }}(\theta)=A_{I I}+A_{I I I}+A_{I V}+A_{V}+A_{V I} \\
& A_{\text {Skid }}(\theta)=\left[\begin{array}{l}
S(W S+(W \cdot \sin (\theta)+L \cdot \cos (\theta))) \\
+0.5 W S \cdot(W \cdot \cos (\theta)+L \cdot \sin (\theta))
\end{array}\right]
\end{aligned}
$$

₹ $\quad$ As defined in Figure A.1, the sum of $\theta+\alpha+\beta+\theta^{\prime}=\pi$. Since $\alpha+\beta$ define a right angle, then the following identity is derived: $\theta=(\pi / 2)-\theta$ '. 


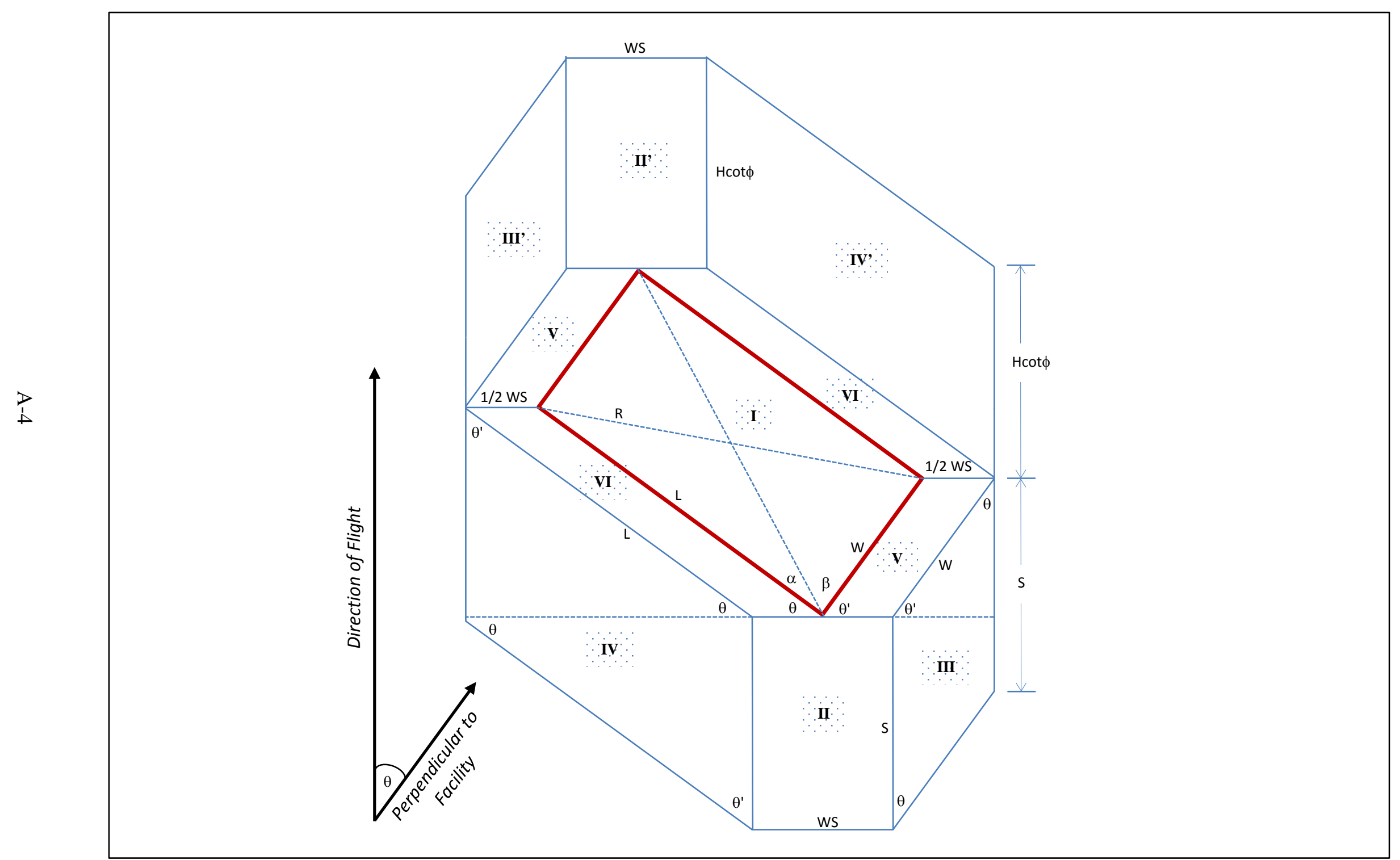

Figure A.1 - Area Elements for Calculating Radially-Averaged Effective Impact Area for a Rectangular Structure 
Derivation of Shadow Area

The shadow area of a rectangular shaped structure is defined in Figure A.1 by (i) rectangle II', and (ii) parallelograms III', IV', V and VI.

\begin{tabular}{|c|c|l|l|}
\hline \multicolumn{3}{|c|}{ Table A.2 - Shadow Area: Rectangle and Parallelogram Elements } \\
\hline Area & Base & Height & \multicolumn{1}{c|}{ Area Equation } \\
\hline II' & $H \cot (\phi)$ & WS & $A_{I I^{\prime}}=H \cot (\phi) \cdot W S$ \\
\hline III' & $H \cot (\phi)$ & W $\sin (\theta)$ & $A_{I I I^{\prime}}=H \cot (\phi) \cdot W \cdot \sin (\theta)$ \\
\hline IV' & $H \cot (\phi)$ & Lcos $(\theta)$ & $A_{I V^{\prime}}=H \cot (\phi) \cdot L \cdot \cos (\theta)$ \\
\hline V & W & $0.5 \mathrm{WS} \cos (\theta)$ & $A_{V}=W \cdot 0.5 W S \cdot \cos (\theta)$ \\
\hline VI & L & $0.5 \mathrm{WS} \sin (\theta)$ & $A_{V I}=L \cdot 0.5 W S \cdot \sin (\theta)$ \\
\hline
\end{tabular}

The total shadow area is expressed as follows:

$$
\begin{aligned}
& A_{\text {Shadow }}(\theta)=A_{I I^{\prime}}+A_{I I I^{\prime}}+A_{I V^{\prime}}+A_{V}+A_{V I} \\
& A_{\text {Shadow }}(\theta)=\left[\begin{array}{c}
H \cot (\phi)(W S+W \cdot \sin (\theta)+L \cdot \cos (\theta)) \\
+0.5 W S(W \cdot \cos (\theta)+L \cdot \sin (\theta))
\end{array}\right]
\end{aligned}
$$

[Eqn. A-3]

Total Effective Impact Area

The total effective impact area is determined as follows:

$$
\begin{aligned}
& A_{\text {eff }}(\theta)=A_{F P}+A_{\text {Skid }}(\theta)+A_{\text {Shadow }}(\theta) \\
& A_{\text {eff }}(\theta)=(L \cdot W)+\left[\begin{array}{c}
(S+H \cot (\phi))(W S+W \cdot \sin (\theta)+L \cdot \cos (\theta)) \\
+W S(W \cdot \cos (\theta)+L \cdot \sin (\theta))
\end{array}\right]
\end{aligned}
$$

\section{A.1.2 Derivation of the Radially-Averaged Effective Impact Area Equation}

Integration of $A_{\text {Skid }}(\theta)$

$$
\begin{aligned}
& \int_{0}^{\pi / 2} A_{\text {Skid }}(\theta) d \theta=\int_{0}^{\pi / 2}\left[\begin{array}{c}
S(W S+W \cdot \sin (\theta)+L \cdot \cos (\theta)) \\
+0.5 W S(W \cdot \cos (\theta)+L \cdot \sin (\theta))
\end{array}\right] d \theta \\
& \int_{0}^{\pi / 2} A_{\text {Skid }}(\theta) d \theta=\left[\begin{array}{c}
S *(\theta \cdot W S-W \cdot \cos (\theta)+L \cdot \sin (\theta)) \\
+0.5 W S(W \cdot \sin (\theta)-L \cdot \cos (\theta))
\end{array}\right]_{0}^{\pi / 2}
\end{aligned}
$$




$$
\int_{0}^{\pi / 2} A_{\text {Skid }}(\theta) d \theta=\left[S\left(\left(\frac{\pi}{2}\right) W S+W+L\right)+0.5 W S(W+L)\right]
$$

$\underline{\text { Integration of } A_{\text {Shadow }}(\theta)}$

$$
\begin{aligned}
& \int_{0}^{\pi / 2} A_{\text {Shadow }}(\theta) d \theta=\int_{0}^{\pi / 2}\left[\begin{array}{c}
H \cot (\phi)(W S+W \cdot \sin (\theta)+L \cdot \cos (\theta)) \\
+0.5 W S(W \cdot \cos (\theta)+L \cdot \sin (\theta))
\end{array}\right] d \theta \\
& \int_{0}^{\pi / 2} A_{\text {Shadow }}(\theta) d \theta=\left[\begin{array}{c}
H \cot (\phi)(\theta \cdot W S-W \cdot \cos (\theta)+L \cdot \sin (\theta)) \\
+0.5 W S(W \cdot \sin (\theta)-L \cdot \cos (\theta))
\end{array}\right]_{0}^{\pi / 2} \\
& \int_{0}^{\pi / 2} A_{\text {Shadow }}(\theta) d \theta=\left[H \cot (\phi)\left(\left(\frac{\pi}{2}\right) W S+W+L\right)+0.5 W S(W+L)\right]
\end{aligned}
$$

[Eqn. A-6]

\section{Derivation of $A_{e f f}(\theta)_{a v g}$}

Substitution of Equations A-1, A-5, and A-6 into Equation 9 yields the following expression for the radially-averaged effective impact area for a rectangular structure:

$$
A_{e f f}(\theta)_{a v g}=(L \cdot W)+\left(\frac{2}{\pi}\right)\left[(S+H \cot (\phi))\left(\left(\frac{\pi}{2}\right) W S+W+L\right)+W S(W+L)\right]
$$

[Eqn. A-7]

\section{A.1.3 Determining the Direction of Flight Corresponding to $A_{\text {eff }}\left(\theta_{\max }\right)$}

The first derivative of $A_{\text {eff }}(\theta)$ is expressed as follows:

$$
\begin{aligned}
& \frac{d}{d \theta}\left(A_{\text {eff }}(\theta)\right)=\frac{d}{d \theta}\left((L \cdot W)+\left[\begin{array}{c}
(S+H \cot (\phi))(W S+(W \cdot \sin (\theta)+L \cdot \cos (\theta))) \\
+W S(W \cdot \cos (\theta)+L \cdot \sin (\theta))
\end{array}\right]\right) \\
& \frac{d}{d \theta}\left(A_{\text {eff }}(\theta)\right)=\left[\begin{array}{c}
(S+H \cot (\phi))((W \cdot \cos (\theta)-L \cdot \sin (\theta))) \\
+W S(-W \cdot \sin (\theta)+L \cdot \cos (\theta))
\end{array}\right]
\end{aligned}
$$

[Eqn. A-8]

As noted in Equation 7, the maximum effective impact area is encountered when the first derivative of $\mathrm{A}_{\text {eff }}(\theta)$ equals zero. Substitution of Equation A-8 into Equation 7 yields: 


$$
\begin{aligned}
& {\left[\begin{array}{c}
(S+H \cot (\phi))\left(\left(W \cdot \cos \left(\theta_{\max }\right)-L \cdot \sin \left(\theta_{\max }\right)\right)\right) \\
+W S\left(-W \cdot \sin \left(\theta_{\max }\right)+L \cdot \cos \left(\theta_{\max }\right)\right)
\end{array}\right]=0} \\
& (S+H \cot (\phi))\left(\left(W \cdot \cos \left(\theta_{\max }\right)-L \cdot \sin \left(\theta_{\max }\right)\right)\right)=W S\left(W \cdot \sin \left(\theta_{\max }\right)-L \cdot \cos \left(\theta_{\max }\right)\right) \\
& \left(\frac{S+H \cot (\phi)}{W S}\right) \cdot\left(\left(W \cdot \cos \left(\theta_{\max }\right)-L \cdot \sin \left(\theta_{\max }\right)\right)\right)=\left(W \cdot \sin \left(\theta_{\max }\right)-L \cdot \cos \left(\theta_{\max }\right)\right)
\end{aligned}
$$

Dividing both sides by $\cos (\theta)$ yields:

$$
\left(\frac{S+H \cot (\phi)}{W S}\right) \cdot\left(W-L \cdot \tan \left(\theta_{\max }\right)\right)=W \cdot \tan \left(\theta_{\max }\right)-L
$$

And upon rearrangement;

$$
\begin{aligned}
& \left(\frac{S+H \cot (\phi)}{W S}\right) \cdot W+L=\left(W+\left(\frac{S+H \cot (\phi)}{W S}\right) \cdot L\right) \tan \left(\theta_{\max }\right) \\
& \tan \left(\theta_{\max }\right)=\left[\frac{\left(\frac{S+H \cot (\phi)}{W S}\right) \cdot W+L}{W+\left(\frac{S+H \cot (\phi)}{W S}\right) \cdot L}\right] \\
& \theta_{\max }=\arctan \left[\frac{\left(\frac{S+H \cot (\phi)}{W S}\right) \cdot\left(\frac{W}{L}\right)+1}{\left(\frac{W}{L}\right)+\left(\frac{S+H \cot (\phi)}{W S}\right)}\right]
\end{aligned}
$$

[Eqn. A-9] 


\section{A.2 METHOD 2: PARALLEL PROJECTION ANALYSIS FOR THE SHADOW AREA AND THE SKID AREA}

This section will demonstrate an alternate approach for determining the shadow area and skid area. The resulting equations will be shown to be equivalent to the shadow area and skid area equations as derived in Section A.1.

\section{Derivation of Shadow Area}

In this method, the effective impact area can be determined by analyzing the planar projection of the following impact surfaces onto the ground (refer to Figure A.2):

- The rear wall

- The obstructed side wall

- The starboard-side wing impact planar surface

- The port-side wing impact planar surface

- The upper rear wall wing impact planar surface

- The obstructed side wall wing impact planar surface

The projection of these impact elements is based on two scalar multipliers: (i) the angle of impact, expressed as $\cot \phi$, and (ii) the compass angle relative to the structure, expressed as $\cos (\theta)$.

- The impact angle multiplier cot $\phi$ is used as a scalar multiplier to determine the length of the shadow projection onto the ground. If a planar surface is parallel to the ground (such an the upper rear wall wing impact planar surface and the obstructed side wall wing impact surface), then a $\cot \phi$ multiplier is not required. The $\cot \phi$ scalar multiplier is only used for the projection of surfaces perpendicular to the ground.

- The compass angle multiplier $\cos (\theta)$ is used as a scalar multiplier to determine the width of the shadow projection onto the ground. The angle $\theta=0$ is defined as a direction of flight directly into (i.e., perpendicular to) the rear wall. The scalar multiplier $\cos (\theta)$ therefore is equal to 1 when $\theta=0$. Since the obstructed side wall is perpendicular to the rear wall, then the compass angle scalar multiplier is offset by $90^{\circ}$. Therefore, the compass angle scalar multiplier for the width of the side wall is $\cos (\pi / 2-\theta)$, which is equivalently expressed as $\sin (\theta)$. 


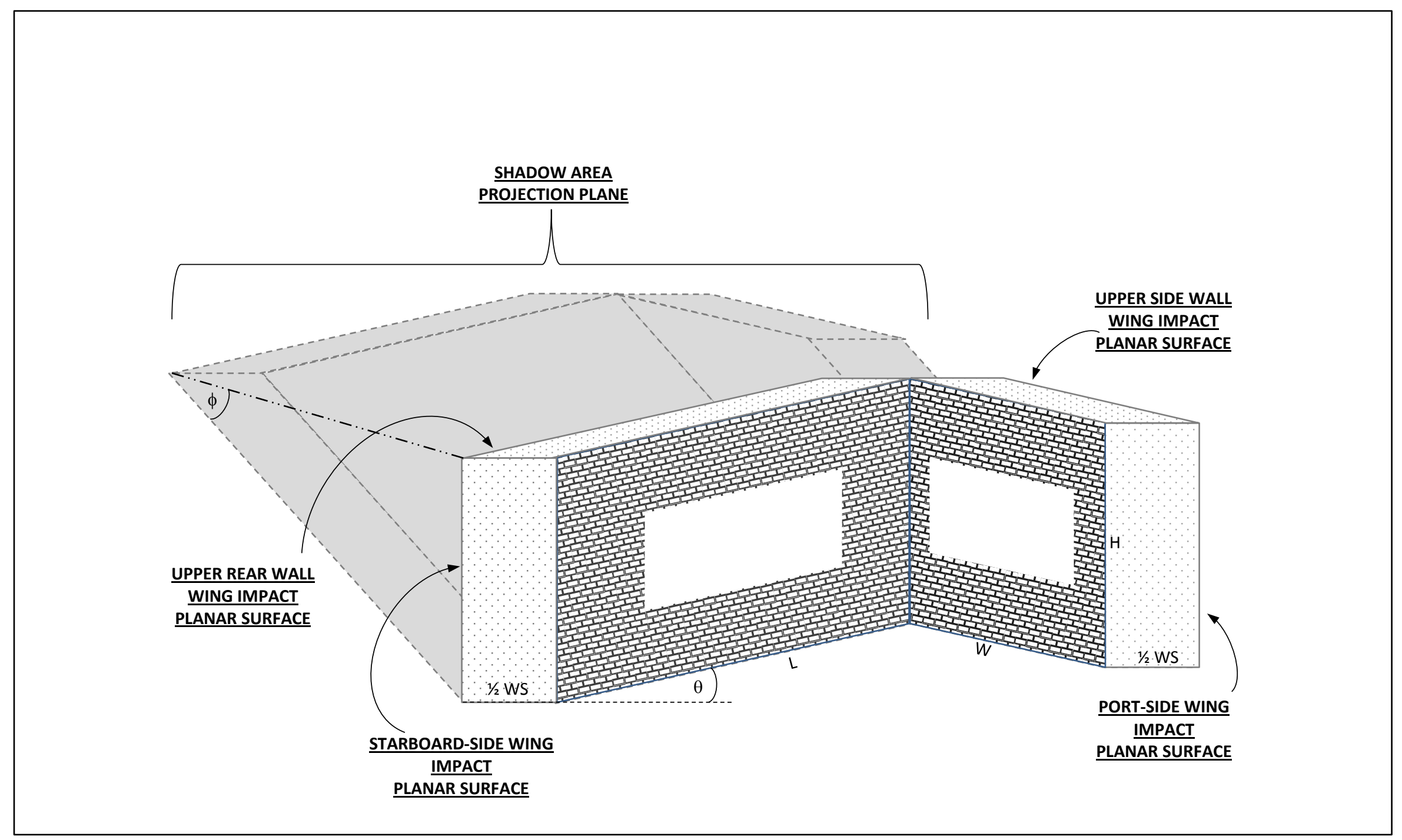

Figure A.2 - Aircraft Impact Shadow Projection 
Using the described scalar multipliers, the planar projection shadow area elements are defined as follows:

\begin{tabular}{|c|c|c|c|}
\hline \multicolumn{4}{|c|}{ Table A.3 - Planar Projection Shadow Area Elements } \\
\hline $\begin{array}{c}\text { Shadow Area Impact } \\
\text { Element }\end{array}$ & $\begin{array}{c}\text { Orientation of Surface } \\
\text { w.r.t. Ground }\end{array}$ & $\begin{array}{c}\text { Element Surface } \\
\text { Area }\end{array}$ & $\begin{array}{c}\text { Projected Surface } \\
\text { Area }\end{array}$ \\
\hline Rear Wall & Perpendicular & $L \cdot H$ & $L \cos (\theta) \cdot H \cot \phi$ \\
\hline Obstructed Side Wall & Perpendicular & $W \cdot H$ & $W \sin (\theta) \cdot H \cot \phi$ \\
\hline $\begin{array}{l}\text { Starboard-side wing impact } \\
\text { planar surface }\end{array}$ & Perpendicular & $\frac{1}{2} W S \cdot H$ & $\frac{1}{2} W S \cdot H \cot \phi$ \\
\hline $\begin{array}{l}\text { Port-side wing impact planar } \\
\text { surface }\end{array}$ & Perpendicular & $\frac{1}{2} W S \cdot H$ & $\frac{1}{2} W S \cdot H \cot \phi$ \\
\hline $\begin{array}{l}\text { Upper rear wall wing impact } \\
\text { planar surface }\end{array}$ & Parallel & $\frac{1}{2} W S \cdot L \cdot \sin (\theta)$ & $\frac{1}{2} W S \cdot L \cdot \sin (\theta)$ \\
\hline $\begin{array}{l}\text { Upper side wall wing impact } \\
\text { planar surface }\end{array}$ & Parallel & $\frac{1}{2} W S \cdot W \cdot \cos (\theta)$ & $\frac{1}{2} W S \cdot W \cdot \cos (\theta)$ \\
\hline
\end{tabular}

The total projected shadow area is expressed by summing the projected shadow area of the individual elements from Table A.3:

$$
A_{\text {Shadow }}(\theta)=\left[\begin{array}{c}
H \cot (\phi)(W S+W \cdot \sin (\theta)+L \cdot \cos (\theta)) \\
+0.5 W S(W \cdot \cos (\theta)+L \cdot \sin (\theta))
\end{array}\right]
$$

[Eqn. A-10]

By inspection, it is observed that the projected shadow area equation (Equation A-10) is identical to the shadow area determine via the geometric analysis in Section A.1 (Equation A-3).

\section{Derivation of Skid Area}

Similar to the derivation of the projected shadow area, the skid area can be determined through a similar approach. The effective impact area can be determined by analyzing the planar projection of the following impact surfaces onto the ground (refer to Figure A.3):

- $\quad$ The front wall

- The unobstructed side wall

- The starboard-side wing impact planar surface

- The port-side wing impact planar surface

- The upper front wall wing impact planar surface

- The unobstructed side wall wing impact planar surface

Similar to the shadow area calculation, the skid area projection utilizes the scalar multiplier $\cos (\theta)$. The angle $\theta=0$ is defined as a direction of flight directly into (i.e., perpendicular to) the front wall. The scalar multiplier $\cos (\theta)$ therefore is equal to 1 when $\theta=0$. Since the unobstructed side wall is perpendicular to the front wall, then the compass angle scalar multiplier is offset by $90^{\circ}$. Therefore, the compass angle scalar multiplier for the width of the side wall is $\cos (\pi / 2-\theta)$, which is equivalently expressed as $\sin (\theta)$. 
One analytical difference between the projected shadow area and the projected skid area is the treatment of the shadow angle. For the shadow area, the shadow angle was defined as the impact angle $\phi$ and the length of the shadow was the scalar quantity, Hcot $\phi$. However for the skid area, the length of the skid shadow is predefined as S. The relationship between $\mathrm{H}$ and $\mathrm{S}$ is therefore expressed as follows:

$$
S=H \cot \varphi
$$

Where:

$$
\varphi \quad=\text { Effective skid area angle }
$$

An example use of this concept can be illustrated analyzing the effective skid area associated with the front wall in Figure A.3. The front wall has an element surface area of $L \cdot H$. When the scalars are applied, the skid area associated with the front wall would be expressed as $L \cos (\theta) \cdot H \cot \varphi$. As previously demonstrated, $S=H \cot \varphi$. Therefore the skid areas associated with the front wall can be equivalently expressed as $L \cos (\theta) \cdot S$.

\begin{tabular}{|c|c|c|c|}
\hline \multicolumn{4}{|c|}{ Table A.4 - Planar Projection Skid Area Elements } \\
\hline $\begin{array}{c}\text { Shadow Area Impact } \\
\text { Element }\end{array}$ & $\begin{array}{c}\text { Orientation of Surface } \\
\text { w.r.t. Ground }\end{array}$ & $\begin{array}{c}\text { Element Surface } \\
\text { Area }\end{array}$ & $\begin{array}{c}\text { Projected Surface } \\
\text { Area }\end{array}$ \\
\hline Front Wall & Perpendicular & $L \cdot H$ & $L \cos (\theta) \cdot S$ \\
\hline Obstructed Side Wall & Perpendicular & $W \cdot H$ & $W \sin (\theta) \cdot S$ \\
\hline $\begin{array}{l}\text { Starboard-side wing impact } \\
\text { planar surface }\end{array}$ & Perpendicular & $\frac{1}{2} W S \cdot H$ & $\frac{1}{2} W S \cdot S$ \\
\hline $\begin{array}{l}\text { Port-side wing impact planar } \\
\text { surface }\end{array}$ & Perpendicular & $\frac{1}{2} W S \cdot H$ & $\frac{1}{2} W S \cdot S$ \\
\hline $\begin{array}{l}\text { Upper rear wall wing impact } \\
\text { planar surface }\end{array}$ & Parallel & $\frac{1}{2} W S \cdot L \cdot \sin (\theta)$ & $\frac{1}{2} W S \cdot L \cdot \sin (\theta)$ \\
\hline $\begin{array}{l}\text { Upper side wall wing impact } \\
\text { planar surface }\end{array}$ & Parallel & $\frac{1}{2} W S \cdot W \cdot \cos (\theta)$ & $\frac{1}{2} W S \cdot W \cdot \cos (\theta)$ \\
\hline
\end{tabular}

Using the described scalar multipliers, the planar projection shadow area elements are defined as follows:

The total projected skid area is expressed by summing the projected skid area of the individual elements from Table A.4:

$$
A_{\text {Shadow }}(\theta)=\left[\begin{array}{l}
S(W S+W \cdot \sin (\theta)+L \cdot \cos (\theta)) \\
+0.5 W S(W \cdot \cos (\theta)+L \cdot \sin (\theta))
\end{array}\right]
$$

By inspection, it is observed that the projected skid area equation (Equation A-11) is identical to the skid area determine via the geometric analysis in Section A.1 (Equation A-2). 


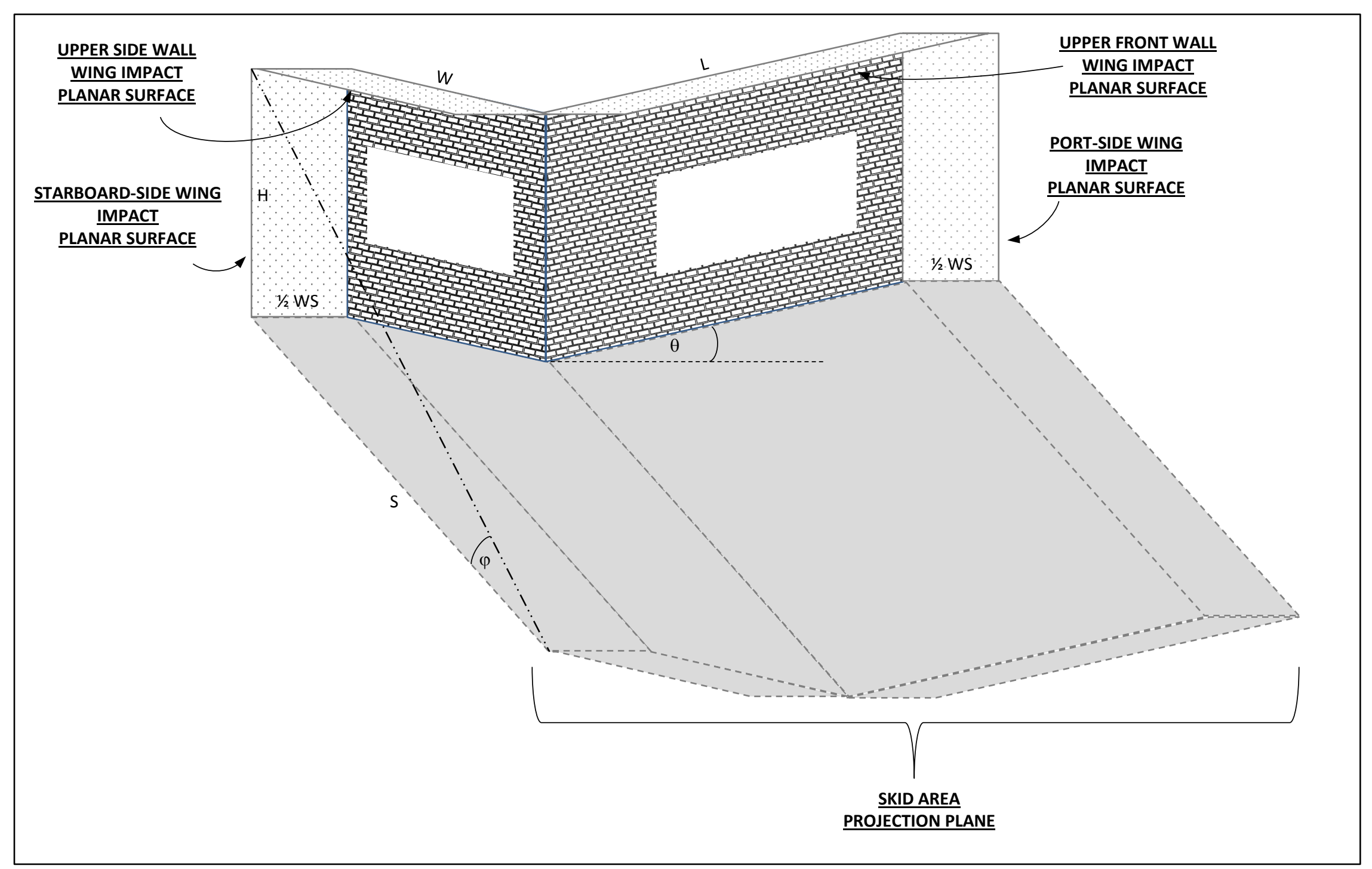

Figure A.3 - Aircraft Impact Skid Area Projection 